\title{
Inhibition of KIF14 Suppresses Tumor Cell Growth and Promotes Apoptosis in Human Glioblastoma
}

\author{
Wei Huang ${ }^{a, b}$ JunYu Wang ${ }^{b}$ Danfeng Zhang ${ }^{b}$ Wen Chen ${ }^{b}$ Lijun Hou \\ Xiaojun $\mathrm{Wu}^{\mathrm{b}}$ Yicheng $\mathrm{Lu}^{\mathrm{b}}$ \\ aDepartment of Neurosurgery, Kunming general Hospital, PLA, Kunming, bepartment of \\ Neurosurgery, Shanghai Changzheng Hospital, Second Military Medical University, Shanghai, China
}

Key Words

KIF14 • Astrocytoma $・$ Cell cycle $・$ Apoptosis $・$ AKT

\begin{abstract}
Background/Aims: The mitotic kinesin superfamily protein KIF14 is essential for cytokinesis and chromosome segregation, and increased KIF14 expression is related to a variety of human cancers. However, the role of KIF14 in the development and malignant progression of astrocytomas and the underlying mechanisms remain unclear. The present study examined the relation between KIF14 and the pathogenesis of malignant astrocytoma. Methods and Results: The role of KIF14 in astrocytoma development and progression was investigated by analyzing KIF14 expression using SYBR Green quantitative real-time RT-PCR, western blotting and immunohistochemistry in human astrocytoma and normal brain tissues. KIF14 expression was higher in astrocytoma samples, and was positively correlated with pathological grade and proliferative activity indicated by Ki-67 staining. SiRNA knockdown of KIF14 inhibited tumor growth in vitro and in vivo, attenuated anchorage-independent growth, and induced G2/M phase arrest, cytokinesis failure and apoptosis in glioblastoma cell lines in association with decreased AKT phosphorylation and activity. Conclusions: The upregulation of KIF14 in astrocytoma is associated with disease severity, and suppression of KIF14 inhibits cell proliferation and induces apoptosis through a mechanism involving the inactivation of AKT signaling, suggesting that KIF14 plays an important role in astrocytoma tumorigenesis and could be a promising molecular target for anticancer therapy.

W. Huang, J. Wang and D. Zhang contributed equally to this work.

Yicheng Lu, PhD, MD

and Xiaojun Wu
Department of Neurosurgery, Shanghai Changzheng Hospital, Second Military Medical

University, 415 Fengyang Road, Shanghai 200003, (China)

E-Mail docluyc@126.com (Y. Lu) and E-Mail docwuxj@126.com (X.Wu) 


\section{Cellular Physiology Cell Physiol Biochem 2015;37:1659-1670

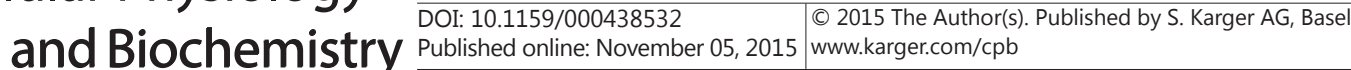 \\ Huang et al.: Oncogenic Role of KIF14 in Human Glioblastoma}

\section{Introduction}

Astrocytic gliomas are the most common cerebral neoplasms, accounting for approximately $80 \%$ of primary malignant tumors of the central nervous system (CNS) [1]. They are divided into four histological grades with different clinical behaviors according to the World Health Organization (WHO) classification: low-grade astrocytomas (grade II), anaplastic astrocytomas (grade III), and glioblastoma (GBM, grade IV), which is the most prevalent and aggressive form of glioma [2]. The current treatment of gliomas includes surgical resection and radiotherapy in combination with adjuvant chemotherapy. However, the prognosis of patients with glioma is poor, and the median overall survival of patients with GBM is $12-15$ months, with only $3-5 \%$ of patients surviving more than 3 years [3]. The recurrence rate of GBM is almost $100 \%$, and patients with recurrent GBM have a median survival of 5-7 months [4]. The cell(s) of origin for the formation of gliomas is currently unknown. One major theory postulates that neural stem cells or neural progenitors undergo transformation when they are in a transit-amplifying phase of development $[5,6]$.

Kinesin superfamily proteins (KIFs) are a conserved class of microtubule-dependent molecular motor proteins that function in the transport of organelles, proteins and mRNA in an ATP-dependent manner. More than $45 \mathrm{KIFs}$ have been described in mice and mammals and they are divided into 15 families that are grouped into three types depending on the position of the motor domain, namely N, M and C kinesins [7, 8]. KIF14, an N-type kinesin belong to the kinesin-3 superfamily [9], is a cytoskeletal protein that plays a role in mitotic spindle formation [10], chromosome segregation [11] and cytokinesis completion [12,13]. Silencing of KIF14 results in alterations in the cell cycle, suggesting that KIF14 plays a role in oncogenesis [14]. KIF14 is overexpressed in several malignancies including hepatocellular and laryngeal carcinomas, and ovarian cancer, and its expression is associated with chemo resistance in triple-negative breast cancer [15-17]. Besides, it is found that KIF14 expression in gliomas is tumor-specific and increased in more aggressive tumors [18].

In the present study, we showed that KIF14 is overexpressed in human malignant astrocytomas and associated with tumor grade. Suppression of KIF14 expression not only inhibited cell growth, clonogenic potential and induced G2/M phase arrest and apoptosis in glioblastoma cell lines, but also inhibited tumor growth in vivo, suggesting that KIF14 plays an important role in astrocytoma tumorigenesis and could be a promising molecular target for anticancer therapy.

\section{Materials and Methods}

\section{Tumor samples and cell culture}

Human primary astrocytoma samples were collected by surgical resection at the Department of Neurosurgery of Changzheng Hospital and then divided to two parts. One part was snap frozen at $-80^{\circ} \mathrm{C}$, and the other part was stored in RNAlater (Ambion, Austin, TX, USA) at $-20^{\circ} \mathrm{C}$ for RNA extraction. Tumors were classified and graded according to the WHO grading system after histopathological analyses. 7 pilocytic astrocytomas (PA, WHO grade I), 15 diffuse astrocytomas (DA, WHO grade II), 9 anaplastic astrocytomas (AA, WHO grade III), and 22 glioblastomas (GBM, WHO grade IV) were surgically resected between 2000 and 2008. The clinicopathological features of all the patients were indicated in Table 1. Normal human brain tissues were obtained from five individuals who had undergone decompressive craniectomy and had no prior pathological conditions. All specimens were examined and stored by the Changzheng Hospital Institutional Review Board. The study was reviewed and approved by the Institutional Review Board of the ShangHai Second Military Medical University, in accordance with the policies of its Ethics Committee. Written informed consent was obtained from all participating patients and all clinical and histopathological data provided to the researchers were rendered anonymous.

The glioblastoma cell lines U373, U251, U138 and U87 were purchased from American Tissue Culture Collection (Manassas, VA, USA) and cultured in Dulbecco's modified Eagle's medium (DMEM) supplemented with $10 \%$ FBS (Gibco, Grand Island, NY) at $37^{\circ} \mathrm{C}$ and $5 \% \mathrm{CO}_{2}$ in a humidified chamber. Normal human 


\section{Cellular Physiology Cell Physiol Biochem 2015;37:1659-1670 \begin{tabular}{ll|l} 
and Biochemistry Published online: November 05, 2015 & $\begin{array}{l}\text { (c) } 2015 \text { The Author(s). Published by S. Karger AG, Basel } \\
\text { www.karger.com/cpb }\end{array}$ \\
\hline
\end{tabular} \\ Huang et al.: Oncogenic Role of KIF14 in Human Glioblastoma}

Table 1. Association of KIF14 expression in human glioma tissues with different clinicopathological features. WHO = World Health Organization, KPS = Karnofsky Performance Scale, NS = not significant

\begin{tabular}{lcccc}
\hline $\begin{array}{l}\text { Clinicopathological } \\
\text { features }\end{array}$ & $\begin{array}{c}\text { No. of } \\
\text { cases }\end{array}$ & \multicolumn{2}{c}{ KIF14 expression } & $p$ Value \\
\hline WHO grade & & & & \\
$\quad$ I & 7 & $2(28.6)$ & $5(71.4)$ & $<0.001$ \\
II & 15 & $8(53.3)$ & $7(46.7)$ & \\
III & 9 & $8(88.9)$ & $1(11.1)$ & \\
IV & 22 & $22(100)$ & $0(0)$ & \\
Age & & & & \\
$\quad<55$ & 23 & $17(73.9)$ & $6(26.1)$ & NS \\
$\geq 55$ & 30 & $23(76.7)$ & $7(23.3)$ & \\
Gender & & & & \\
Male & 32 & $25(78.1)$ & $7(21.9)$ & NS \\
Female & 21 & $15(71.4)$ & $6(28.6)$ & \\
KPS & & & & \\
$<80$ & 29 & $26(89.7)$ & $3(10.3)$ & 0.02 \\
$\geq 80$ & 24 & $14(58.3)$ & $10(41.7)$ & \\
Ki-67 index & & & & \\
$<10$ & 23 & $14(60.9)$ & $9(39.1)$ & $<0.001$ \\
$\geq 10$ & 30 & $26(86.7)$ & $4(13.3)$ & \\
\hline
\end{tabular}

astrocytes (NHA) from Clonetics primary cell systems (Lonza, Basel, Switzerland) were cultured in astrocyte basal medium supplemented with the EGM SingleQuots (Lonza).

Immunohistochemistry

Formalin-fixed, paraffin-embedded, $3 \mu \mathrm{m}$ tissue sections were deparaffinized in xylol and rehydrated in a graded ethanol series. Antigen retrieval was performed by the microwave heating method for 20 min with Tris-EDTA buffer (10 mM Tris-HCl, pH 9.0; 1 mM EDTA). Endogenous peroxidase activity was eliminated by incubation with 3\% methanolic hydrogen peroxide solution for $30 \mathrm{~min}$. The slides were incubated in nonimmune serum for 30 min. Rabbit anti-KIF14 polyclonal antibody (ab71155, 1:1,000; Abcam, Cambridge, UK) and anti-Ki-67 primary antibody (ab15580; 1:200; Abcam) were added and the sections were incubated overnight at $4^{\circ} \mathrm{C}$. After washing in TBST (150 mM NaCl, $10 \mathrm{mM}$ Tris- $\mathrm{HCl}(\mathrm{pH}$ 7.6), $0.1 \%$ Tween 20 ), the sections were incubated with biotin-conjugated secondary antibody for $20 \mathrm{~min}$ at room temperature, followed by peroxidase-conjugated biotin streptavidin complex (Dako, Glostrup, Denmark) for 20 min, and finally visualized with 3, 3'-diaminobenzidine and counterstained with hematoxylin. To ensure the specificity of the immunostaining, sections in which the primary antibody was replaced by nonimmune serum were used as a negative control.

\section{Real-time qPCR analysis}

Total RNA was isolated from human astrocytoma tissues preserved in RNAlater (Ambion) using the RNeasy kit according to the manufacturer's protocol (Qiagen, Valencia, CA, USA). Briefly, first-strand cDNA was reverse-transcribed from $1 \mu \mathrm{g}$ total RNA using the Super-Script First-Strand cDNA System (Invitrogen, Carlsbad, CA, USA), and amplified by Platinum SYBR Green qPCR SuperMix-UDG (Invitrogen). A master mix was prepared for each PCR reaction, which included Platinum SYBR Green qPCR SuperMix-UDG, forward primer, reverse primer and $10 \mathrm{ng}$ of template cDNA. PCR conditions were $5 \mathrm{~min}$ at $95^{\circ} \mathrm{C}$, followed by 50 cycles at $95^{\circ} \mathrm{C}$ for $15 \mathrm{~s}$ and $60^{\circ} \mathrm{C}$ for $1 \mathrm{~min}$ and $72^{\circ} \mathrm{C}$ for $30 \mathrm{~s}$. The forward and reverse primer sequences for KIF14 were 5' - TGG TGA AAT GGC CTG TAC AAG T-3' and 5'-GGC AAC CAG TTA ACC CTT TGA G-3'. The primer 


\section{Cellular Physiology Cell Physiol Biochem 2015;37:1659-1670 \begin{tabular}{c|c|c|c|} 
DOI: 10.1159/000438532 & O 2015 The Author(s). Published by S. Karger AG, Basel \\
and Biochemerger.com/cpb
\end{tabular} \\ Huang et al.: Oncogenic Role of KIF14 in Human Glioblastoma}

sequences for human $\beta$-actin were 5'-CAC GAT GGA GGG GCC GGA CTC ATC-3' (forward) and 5'-TAA AGA CCT CTA TGC CAA CAC AGT-3' (reverse).

Western blotting

Western blot analysis was performed on $50 \mu \mathrm{g}$ of protein lysates from each sample according to a standard protocol [19] using anti-KIF14 (ab71155, 1:2,000), anti-pAKT (S473, ab81283, 1:5,000; T308, ab66134, 1:3,000), anti-AKT (ab32505, 1:5,000), anti-active + pro-caspase 3 (ab13847,1:2,000), anti-cleaved PARP (ab4830, 1:2,000) and anti-PARP (ab6079, 1:400) antibodies, followed by incubation with secondary horseradish peroxidase antibody (ab6721, 1:3,000) and detection with the Enhanced Chemiluminescence Kit (Amersham Pharmacia Biotech). Mouse monoclonal anti- $\beta$-actin (ab75186, 1:1,000) was used as the loading control. All antibodies were purchased from Abcam.

\section{Immunofluorescence/confocal microscopy}

Adherent U251 glioma cells were cultured on sterile cover glasses in DMEM media with 10\% FBS. The cells were fixed with $2 \%$ paraformaldehyde, permeabilized with $0.2 \%$ Triton-X and incubated with antiKIF14 (ab71155, 1:1,000; Abcam) for $2 \mathrm{~h}$ in a humidified chamber at $37^{\circ} \mathrm{C}$. The slides were washed three times in PBS and incubated with secondary antibodies containing mixtures of cy3-conjugated anti-rabbit IgG (ab6939, 1:1,000; Abcam) for 60 min. Finally, the cells were washed three times in PBS and mounted with ProLong Gold antifade reagent (Invitrogen, Camarillo, CA, USA). Under certain circumstances, cells were counterstained with the blue nuclear dye Hoechst 33258. Samples were visualized using a Zeiss LSM 5 PASCAL laser scanning confocal microscope. For $\alpha$-tubulin/DAPI staining, cells were stained with an anti$\alpha$-tubulin (ab71155, 1:1,000; Abcam), followed by an anti-rabbit Alexa 488 secondary antibody (ab150077, 1:1000; Abcam), and nuclei visualized by DAPI (Sigma, St. Louis, MO, USA). The binucleated cell fraction was calculated in five fields for each group.

\section{Constructs and transfection}

Chemically synthesized KIF14 siRNA were purchased from Dharmacon/Thermo Scientific (si-KIF14-1: J-003319-06, si-KIF14-2: J-003319-05). Unless specified, si-KIF14 refers to J-003319-06. In vitro transient transfection was performed using Lipofectamine 2000 (Invitrogen) following the manufacturer's protocol.

\section{Cell proliferation assay}

Cell proliferation was determined by the 3-(4, 5,-dimethylthiazol-2-yl)-2, 5- diphenyltetrazolium bromide (MTT) assay. Cells were plated onto 96-well culture plates and cultured overnight for cell attachment. At daily intervals $(24,48,72,96$, and $120 \mathrm{~h})$, the number of viable cells was determined by MTT assay as described previously $[20,21]$. Absorbance was measured at $570 \mathrm{~nm}$ on a microplate reader. Three independent experiments were performed.

\section{Colony formation assay}

Substrate-independent cell proliferation was determined by soft agar colony formation assays performed in 6-well plates with a $1.5-\mathrm{mL}$ bottom layer and $0.5-\mathrm{mL}$ top layer containing $5.1 \mathrm{mg} / \mathrm{mL}$ agar (Difco Laboratories, Detroit, MI) in culture medium (DMEM plus supplements). Cells $\left(1 \times 10^{4} /\right.$ well) were dispersed as a single cell suspension in culture medium with $3.4 \mathrm{mg} / \mathrm{mL}$ agar, overlaid onto the bottom agar layer, and covered by the top layer. Cells were incubated for 2 to $3 \mathrm{~h}$ at room temperature and then at $37^{\circ} \mathrm{C}$ under $5 \% \mathrm{CO}_{2}$. The top layer was covered with $400 \mu \mathrm{L}$ of fresh culture medium every second day. Colony formation was quantified after 10 days using Giemsa staining.

\section{Apoptosis assay}

The rate of apoptosis was assessed using a MEBCYTO Apoptosis Kit (Medical and Biological Laboratories Co., Ltd, Aichi, Japan) according to the manufacturer's instructions. In brief, $1 \times 10^{5}$ cells were trypsinized, washed with PBS, and stained with Annexin V-fluorescein isothiocyanate (FITC) and PI in the dark for 15 $\mathrm{min}$ at room temperature. The stained cells were then analyzed by flow cytometry (BD FACSCalibur, Becton Dickinson, San Jose, CA). The frequency of Annexin V-positive apoptotic cells was expressed as a percentage of the total number of cells counted. 


\section{Cellular Physiology Cell Physiol Biochem 2015;37:1659-1670 \begin{tabular}{l|l|l} 
DOI: $10.1159 / 000438532$ & (c) 2015 The Author(s). Published by S. Karger AG, Basel \\
wiochemistry
\end{tabular} \\ Huang et al.: Oncogenic Role of KIF14 in Human Glioblastoma}

Cell cycle assay

SiRNA-transfected cells and untransfected control cells were trypsinized, collected, washed, and suspended in cold PBS. On the day of analysis, cells were centrifuged at 1,000 rpm for 5 min, resuspended in $0.5 \mathrm{~mL}$ PBS, fixed in $4.5 \mathrm{~mL} 70 \%$ ice-cold ethanol, and stored at $4{ }^{\circ} \mathrm{C}$. The cell suspension was then incubated in $0.2 \mathrm{mg} / \mathrm{mL}$ propidium iodide (PI) containing $0.1 \%$ Triton X-100 and RNase A ( $1 \mathrm{mg} / \mathrm{mL}$, both from Sigma) in the dark for $30 \mathrm{~min}$ at room temperature. Cell cycle distribution was determined using fluorescenceactivated cell sorting (FACS) analysis (FACSCalibur, BD Biosciences).

Nude mouse tumor xenograft model and treatment

U251 glioma cells were subcutaneously injected into 5-week-old female nude mice. When the tumor volume reached $50 \mathrm{~mm}^{3}$, the mice were randomly divided into four groups ( $\mathrm{n}=5$ per group). Each group was treated with KIF14 siRNA or nonsense siRNA through local injection of the xenograft tumor at multiple sites. Tumor size was measured every 3 days post injection, and the total volume was calculated using the formula: volume $=$ length $\times$ width $2 / 2[22,23]$.

\section{Statistics}

All data were expressed as the mean \pm standard deviation (SD) of three independent experiments. Comparisons between two groups were performed using the Student's t-test, and comparisons between three or more groups were performed using analysis of variance (ANOVA) followed by Dunnett's t-test. Immunoblot bands were visualized and quantified by ImageJ software (NIH, USA). $p<0.05$ was considered statistically significant.

\section{Results}

KIF14 is upregulated in astrocytoma tissues and glioblastoma cell lines

Quantitative real time PCR analysis showed that KIF14 expression levels were significantly higher in malignant $(n=31)$ and low-grade $(\mathrm{n}=22)$ astrocytomas than in normal brain tissues $(\mathrm{n}=5)(p<0.01)$ (Fig. 1A). Western blot analysis confirmed that KIF14 expression levels increased in correlation with the severity of astrocytoma (Fig. 1B). KIF14 expression was significantly higher in glioblastoma cell lines than in the normal astrocytes (NHA) (Fig. 1C).

The cellular localization of the KIF14 protein in human astrocytoma tissues was examined by immunohistochemistry. As shown in Fig. 2A, KIF14 immunoreactivity was predominantly detected in the cytoplasm

Fig. 1. Expression of KIF14 in human glioma tissues and cell lines. (A) qPCR analysis of KIF14 expression in high grade (WHO III and IV) and low grade (WHO I and II) glioma samples. (B) Western blot analysis of KIF14 expression in gliomas of different grades and normal brain tissues (NC). (C) Western blot analysis of KIF14 protein levels in various glioma cell lines and normal astrocytes (NHA). ${ }^{*} p<0.05,{ }^{* *} p<0.01$.

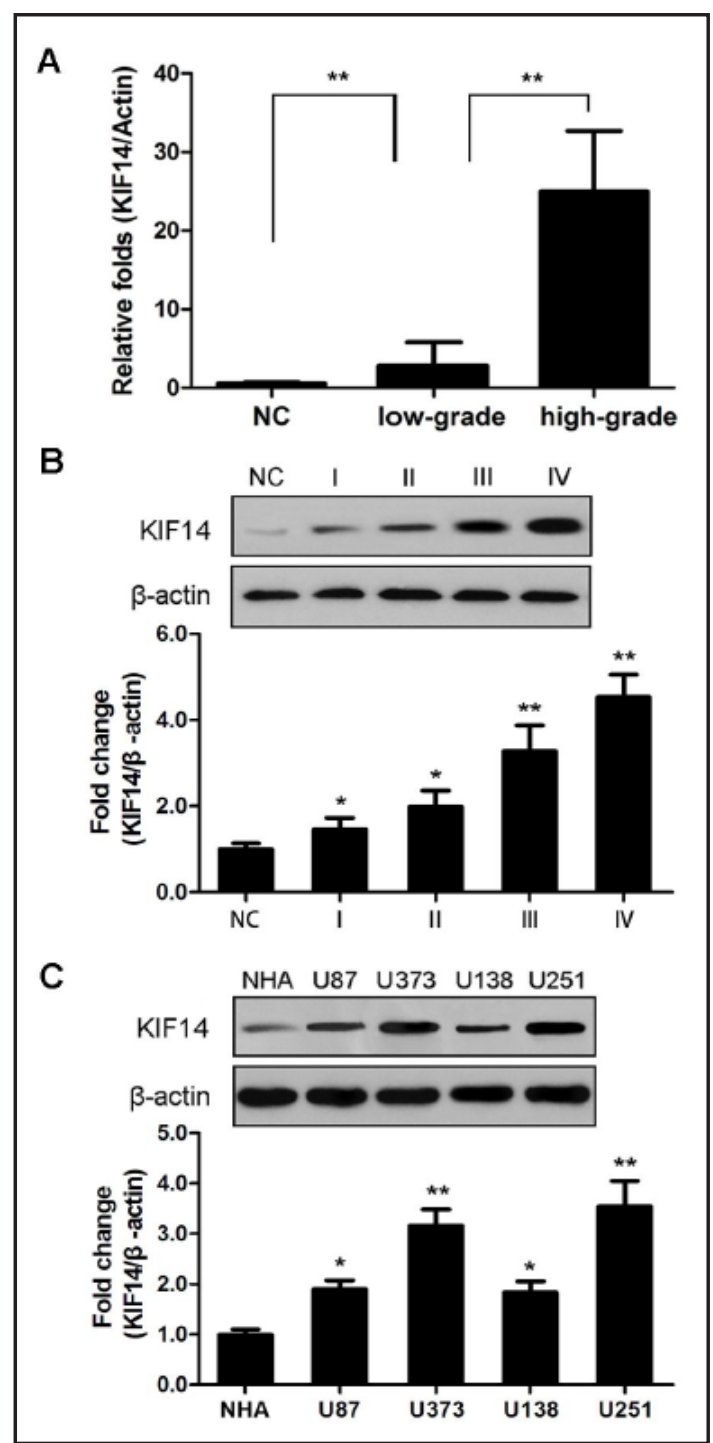




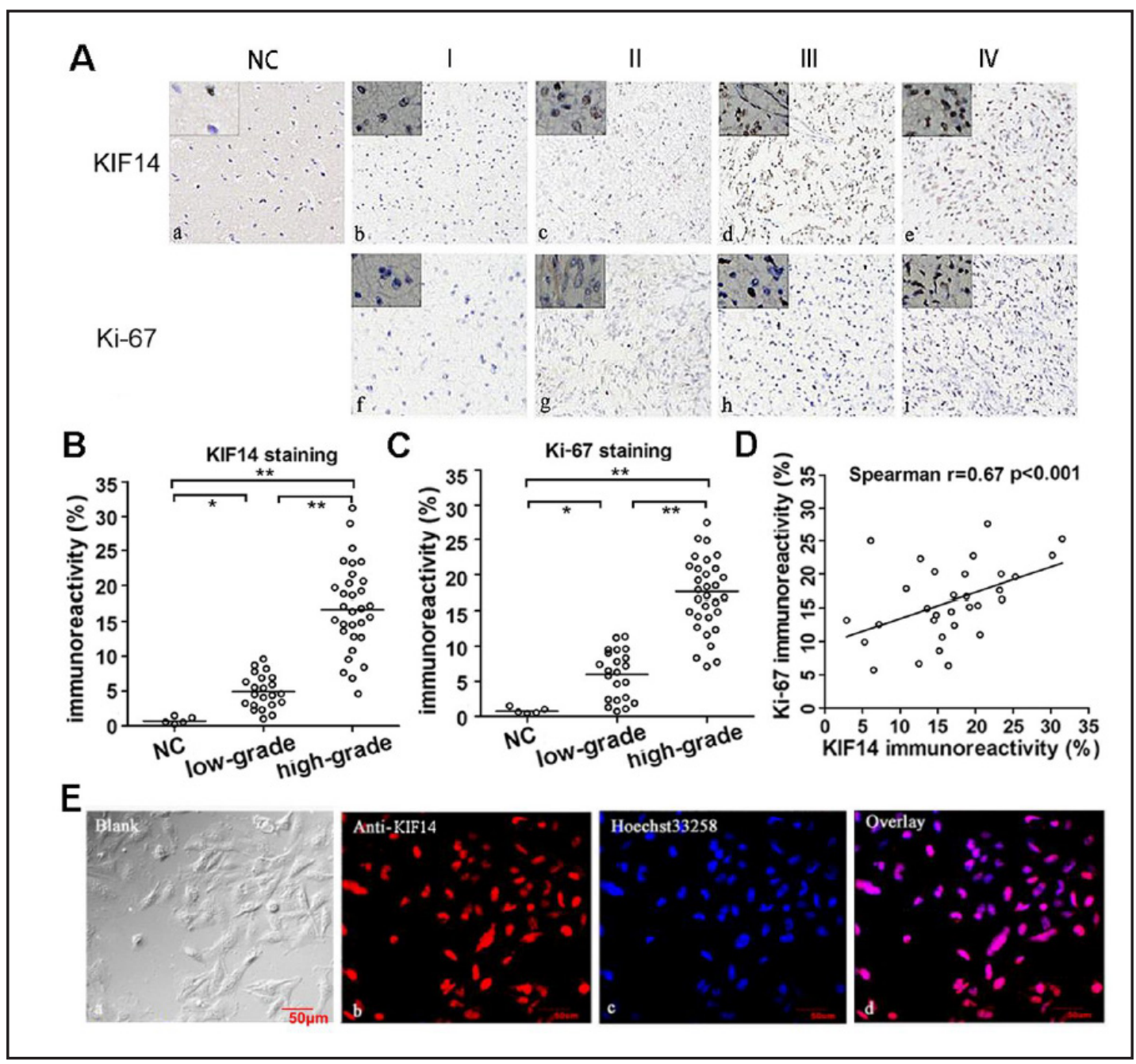

Fig. 2. Immunohistochemical analysis of KIF14 and Ki-67 expression in astrocytomas. (A) Weak staining for KIF14 staining was weak in normal brain tissues (a) and strong cytoplasm and/or nuclear KIF14 staining was noted in high grade glioma $(d, e)$ compared to low grade glioma $(b, c)$. Stronger nuclear staining for Ki-67 were noted in high grade glioma (h, i) than that in low grade glioma (f, g). KIF14 (B) and Ki-67 (C) immunoreactivity in astrocytomas was positively correlated with tumor grade. ${ }^{*} p<0.05,{ }^{* *} p<0.01$. (D) Positive correlation between KIF14 and Ki-67 labeling index. (E) Immunofluorescence/confocal microscopy assay showing the localization of KIF14 and Hoechst33258 in U251 glioma cells. Scale bar $=50 \mu \mathrm{m}$.

and/or nucleus of malignant astrocytoma tissues (d, e), whereas weakly positive staining for KIF14 was observed in normal brain tissues (a). Statistical analysis showed that the KIF14 labeling index was significantly higher in high-grade astrocytomas than in low-grade tumors $(16.67 \pm 6.89 \%$ vs. $4.95 \pm 2.92 \%$, respectively; $p<0.01)$ and normal controls $(16.67 \pm 6.89 \%$ vs. $0.60 \pm 0.41 \%$, respectively; $p<0.01$ ). The semi-quantitative results of KIF14 and Ki-67 immunostaining are shown in Fig. 2B and Fig. 2C. KIF14 staining was positively correlated with proliferative activity as indicated by Ki-67 staining $(p<0.01 ; \mathrm{r}=0.67$, Spearman's correlation coefficient) (Fig. 2D). Immunofluorescence/confocal microscopy analysis showed that KIF14 localized to the cytoplasm and/or nucleus of U251 glioma cells (Fig. 2E), confirming the immunohistochemical detection of KIF14 in the cytoplasm and/or nucleus of astrocytoma cells.

The associations of KIF14 expression with the clinicopathological features of gliomas are summarized in Table 1. The high level of KIF14 expression was significantly correlated 


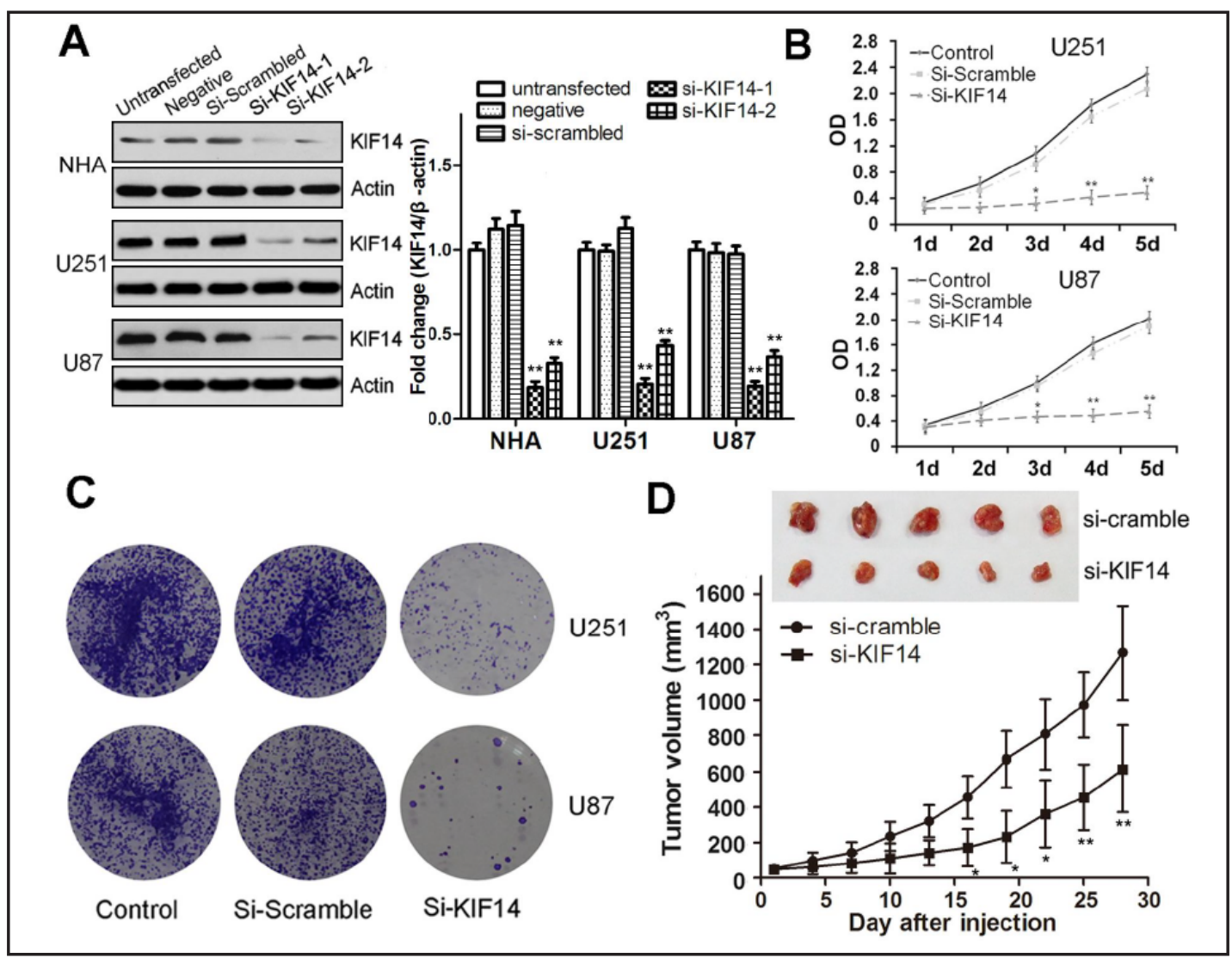

Fig. 3. Effects of KIF14 expression on glioblastoma cell growth and cell cycle. Western blot analysis of KIF14 expression (A) and MTT cell proliferation assays (B) in U251 and U87 glioblastoma cells transfected with siRNA targeting KIF14 or scrambled siRNA for $24 \mathrm{~h}$. (C) Colony formation assays in U251 and U87 glioblastoma cells showed that KIF14 knockdown resulted in a significant decrease in colony number compared with the control groups. (D) Effect of KIF14 knockdown on tumor growth in vivo. Left panel: Final tumor photographs at 35 days post-subcutaneous injection. Right panel: average tumor volume during treatment. The bars represent the means \pm SD of five mice per group.

with advanced pathological grade $(p<0.001)$, low Karnofsky Performance Scale score (KPS, $p=0.02)$ and high Ki-67 index ( $p<0.001)$. However, no statistically significant association of KIF14 with age at diagnosis and gender of patients was found (both $p>0.05$ ).

Effects of KIF14 inhibition on cell proliferation in vitro and xenograft tumor formation in vivo

The effect of two KIF14 siRNAs was examined by western blotting, which showed that the protein levels of KIF14 were significantly lower in KIF14-siRNA transfected cells than in uninfected glioma cells and negative controls, and si-KIF14-1 suppressed KIF14 expression most efficiently (Fig. 3A). Therefore, all of the downstream assays were performed using siKIF14-1 (hereafter referred to as si-KIF14). The results of MTT assay showed that the rate of proliferation of U251 and U87 cells was significantly lower in KIF14-siRNA transfected cells than in uninfected parental cells or negative controls (Fig. 3B). Colony formation assays further demonstrated that knockdown of KIF14 in U251 or U87 cells significantly inhibited colony formation (Fig. 3C). The effect of KIF14 silencing on tumor growth inhibition was confirmed in vivo in a U251 xenograft model. At the termination of the study, tumor volume was significantly lower in si-KIF14 tumors than in si-scramble control tumors (Fig. 3D).

\section{KARGER}




\section{Cellular Physiology and Biochemistry

Fig. 4. Effect of KIF14 inhibition on cell cycle progression. (A) Effect of KIF14 siRNA on cell cycle distribution. Diagrams showing an increase in the proportion of cells in G2/M phase in both U251 and U87 cells treated with siRNA against KIF14. (B) Effects of KIF14 siRNA on cytokinesis. Representive images showed the binucleate cells in the three groups. Scale bar $=50 \mu \mathrm{m}$. (C) The bar chart represents the average frequencies of the binucleate cells in the control, si-scramble and si-KIF14 group cells. ${ }^{*} p<0.05$.

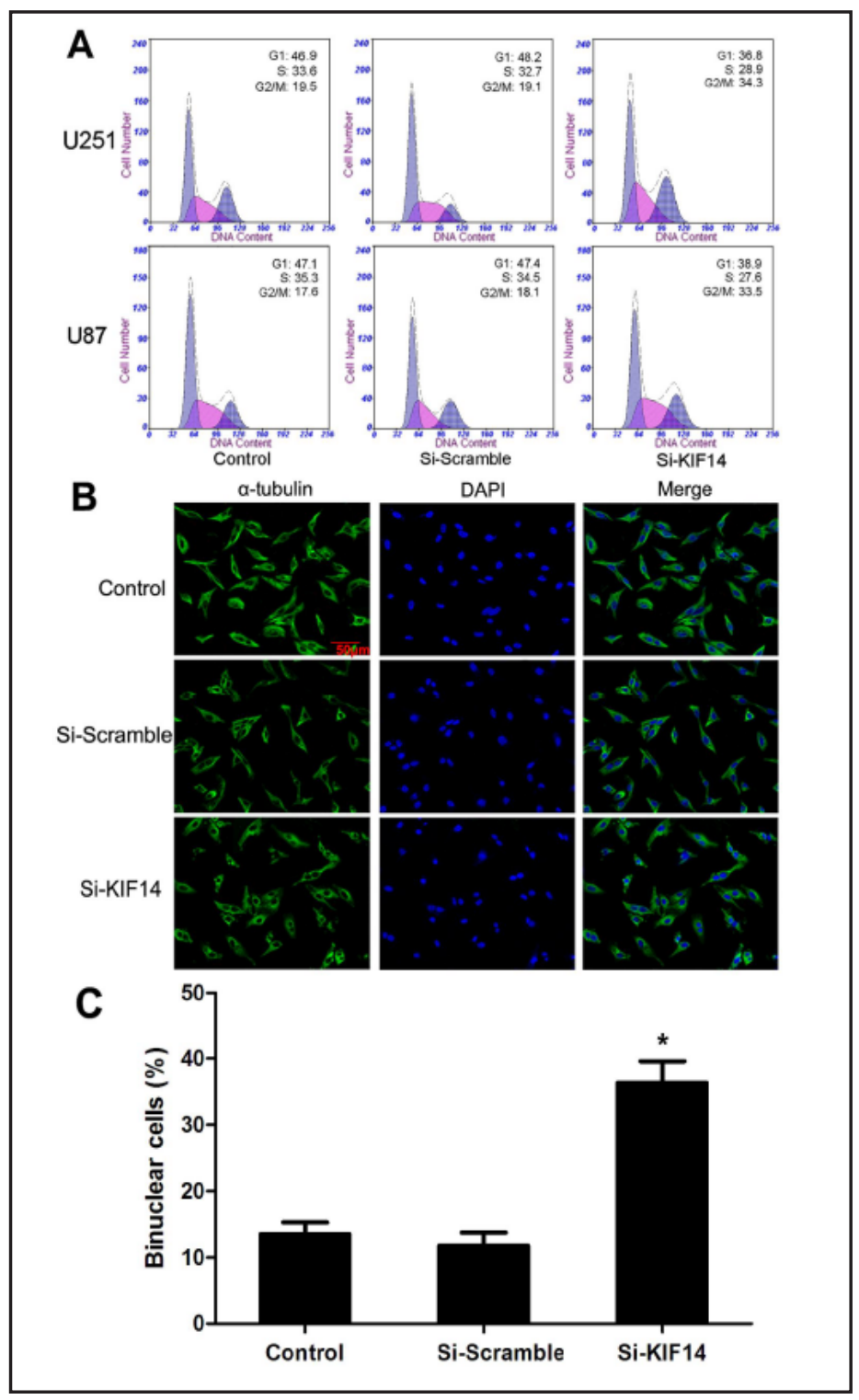

Effects of KIF14 inhibition on cell cycle progression

The effect of KIF14 silencing on cell cycle progression was examined by measuring the DNA content in PI-stained cells by flow cytometry and counting the fraction of cells in G1, $\mathrm{S}$ and G2/M phases (Fig. 4A). The fraction of cells in G2/M phase was significantly higher in glioma cell lines infected with KIF14-siRNA (34.3\% in U251 cells and 33.5\% in U87 cells) than in uninfected cells (19.5\% in U251 cells and $17.6 \%$ in U87 cells), indicating that silencing of KIF14 by siRNA induced the G2/M phase arrest in both U251 and U87 cells. Since KIF14 is involved in mitotic spindle assembly [10], the effect of KIF14 silencing on cytokinesis was further evaluated by $\alpha$-tubulin/DAPI staining in U251 cells (Fig. 4B). Besides, the binucleate cell fraction was measured, and the fraction of binucleate cells in the KIF14siRNA transfected cells was significantly higher than that in untranfected and si-scramble transfected cells $(36.5 \%$ vs. $14.2 \%$ and $12.1 \%, p<0.05$; Fig. 4 C), suggesting that cells with KIF14 silencing more prone to cytokinesis failure.

KIF14 inhibition induces apoptosis via inactivation of Akt kinase

AnnexinV/PI staining showed a significantly greater number of apoptotic cells in glioblastoma cell suspensions infected with siRNA against KIF14 than in the control groups 
Fig. 5. Effects of KIF14 expression on apoptosis in glioblastoma cell lines. (A) Apoptosis in U251 and U87 cells was measured by Annexin $\mathrm{V} /$ propidium iodide (PI) staining following siRNA inhibition. (B) Early apoptotic cell populations were significantly increased $\left({ }^{* *} \mathrm{p}<0.01\right)$ after siRNA transfection.

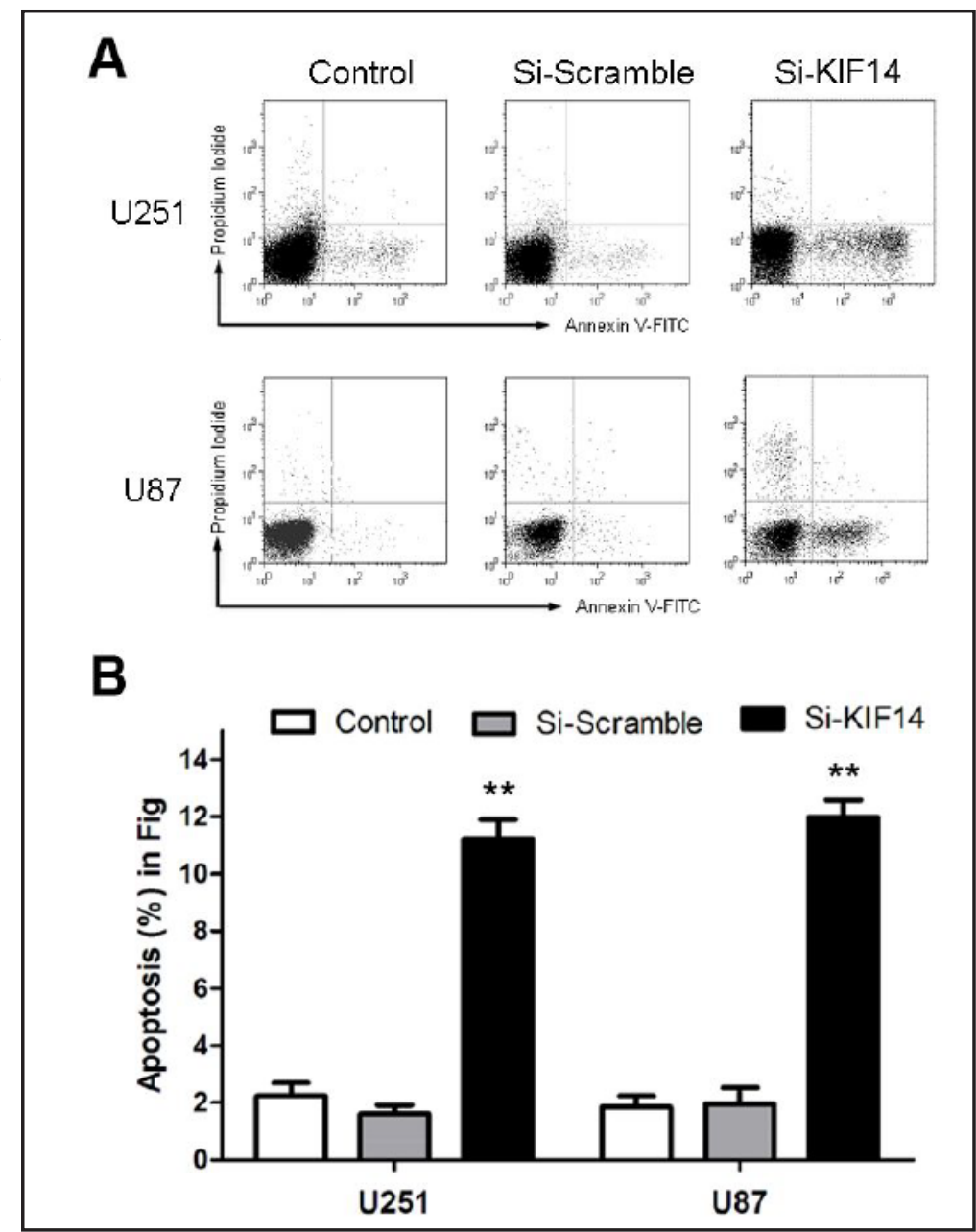

(Fig. 5). To further explore the mechanisms by which KIF14 depletion induces apoptosis of glioblastoma cells, the activity of signaling pathways associated with apoptosis was examined by western blotting in cells subjected to KIF14 knockdown. As shown in Fig. 6, suppression of KIF14 expression caused a time-dependent downregulation of both cleaved caspase- 3 and cleaved PARP, as well as phosphorylated or activated Akt at Ser473 and T308 in U251 and U87 cell lines. These results indicate that KFI14 silencing may inhibit cell survival by suppressing AKT activation in glioblastoma cells.

\section{Discussion}

KIF14 plays important roles in cell cycle progression and mitosis, and deregulation of KIF14 has been implicated in the development and progression of several human malignancies. In the present study, we examined the significance of KIF14 in the progression of malignant astrocytoma in vitro and in vivo. Our results showed that KIF14 is overexpressed in astrocytoma and associated with the degree of malignancy, and KIF14 expression is correlated with proliferative activity. Knockdown experiments showed that suppression of KIF14 inhibits cell proliferation and induces apoptosis through the inactivation of AKT signaling.

KIF14 was initially cloned in 1994 and since then shown to be an important molecular motor characterized by a C-terminal citron kinase binding domain and an N-terminal motor domain that shows a distinct mechanism of binding to microtubules [24, 25]. KIF14 has been referred to as an oncogenic kinesin because it is overexpressed in many cancers 


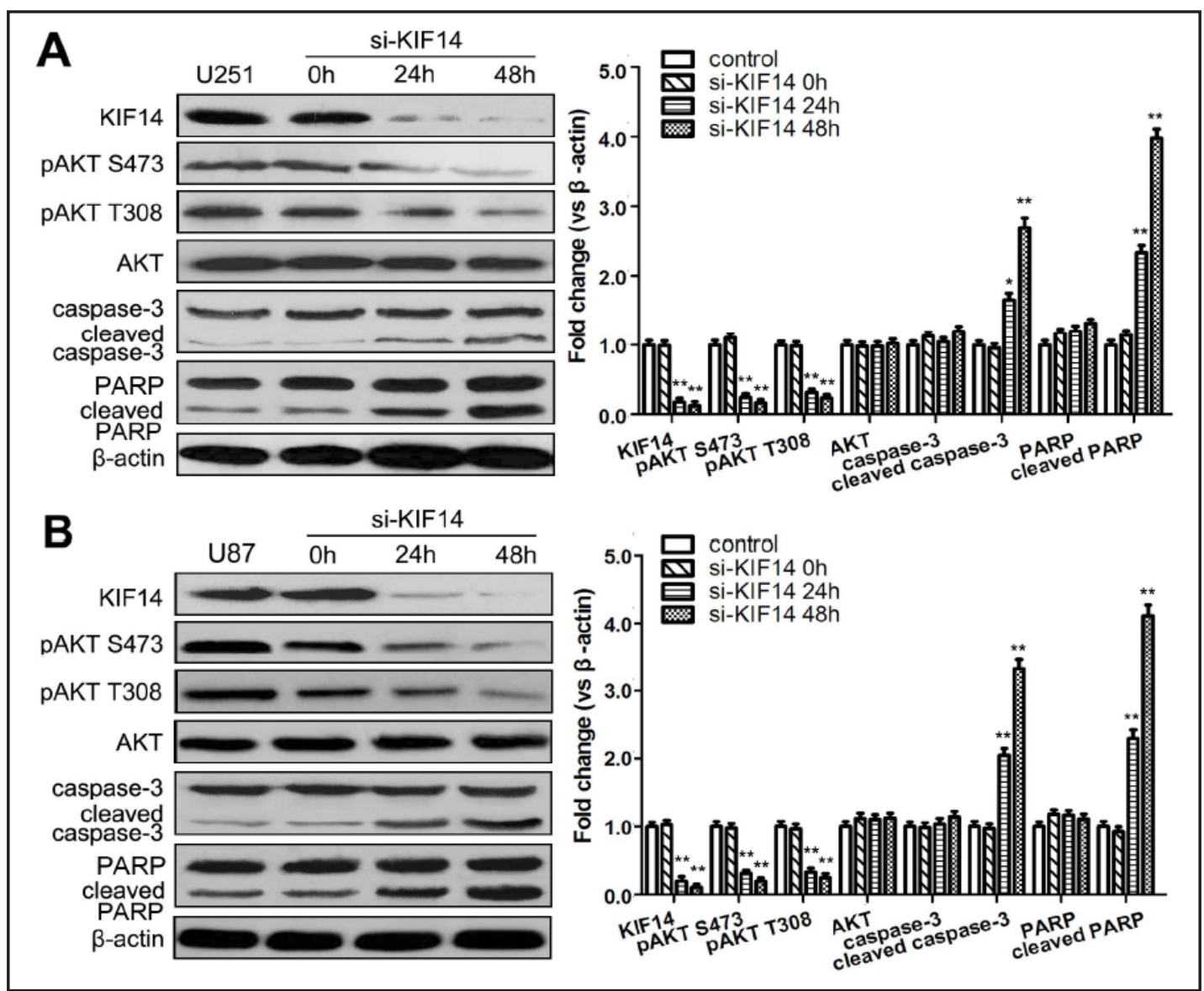

Fig. 6. Effects of KIF14 siRNA on AKT activation in glioblastoma cell lines. Western blot analysis of KIF14, pAKT (S473, T308) and total AKT, cleaved and total caspase-3, cleaved and total PARP in response to KIF14 silencing for different times in U251 (A) and U87 (B) cells.

and is correlated with poor prognosis [26-28]. KIF14 overexpression in lung and breast cancer predicts patient outcome [29, 30], and KIF14 is overexpressed in primary human retinoblastoma, in particular in older patients [31]. In ovarian cancer, high KIF14 expression predicts poor outcome and is associated with increased recurrence rates [32]. However, the mechanism by which KIF14 mediates tumorigenesis is not clear, although it is thought to be related to its role in mitosis. KIF14 expression varies during the cell cycle, with peak expression in S phase, and silencing of KIF14 produces distinct phenotypes depending on the degree of knockdown of the kinesin [10].

The involvement of KIF14 in glioma development or progression was demonstrated in a study that showed that KIF14 is upregulated at the transcriptional level in gliomas, and its overexpression is associated with advanced pathological grade, low Karnofsky performance score, high mitotic and Ki-67 indexes, and poor survival of patients [18]. These results are consistent with the findings of the present study showing that KIF14 expression is correlated with Ki-67 immunostaining in glioma cell lines. Furthermore, KIF14 knockdown inhibited cell proliferation, induced G2/M phase arrest, promoted apoptosis and inhibited tumor growth in vivo. In hepatocellular carcinoma (HCC) cells, knockdown of KIF14 suppressed cell proliferation, caused failure of cytokinesis, and downregulated cyclins E1, D1 and B1, whereas KIF14 overexpression promoted cell proliferation [14]. These effects were found to be mediated by the modulation of the expression of Skp2 and Cks1, which target $\mathrm{p} 27^{\text {Kip } 1}$ for degradation by the $26 \mathrm{~S}$ proteasome. In another recent study, KIF14 was found to be overexpressed in HCC and associated with tumor grade, and silencing of KIF14 induced apoptosis by inactivating the phosphatidylinositol 3-kinase-Akt (PI3K/AKT) signaling KARGER 


\section{Cellular Physiology Cell Physiol Biochem 2015;37:1659-1670 \begin{tabular}{l|l|l|l} 
DOI: 10.1159/000438532 & $\begin{array}{l}\text { @ } 2015 \text { The Author(s). Published by S. Karger AG, Basel } \\
\text { www.karger.com/cpb }\end{array}$
\end{tabular} \\ Huang et al.: Oncogenic Role of KIF14 in Human Glioblastoma}

pathway [33]. The results of the present study support the findings in HCC by showing that KIF14 knockdown inhibited the S473 and T308 phosphorylation of AKT in glioma cells, suggesting a mechanism underlying the tumorigenic effect of KIF14 in astrocytoma. Similar results were obtained in triple negative breast cancer, where KIF14 knockdown inhibited the expression of pAKT S473 and pAKT T308, indicating that KIF14 plays a role in the activation of PI3K/AKT signaling in breast cancer [34]. Taken together with previous findings, our results suggest that KIF14 could be an attractive therapeutic target for the treatment of glioma, which warrants further investigation into the effects of KIF14 knockdown and the underlying mechanisms in in vitro and in vivo models.

\section{Acknowledgments}

This work was supported by the National Natural Science Foundation of China (No. 30930094), National Nature Science Foundation of Shanghai (No.15ZR1414500) and National Natural Science Foundation of China for Youth (No. 81302188).

\section{Disclosure Statement}

The authors declare no competing interests.

\section{References}

1 Taylor LP: Diagnosis, treatment, and prognosis of glioma: five new things. Neurology 2010;75:S28-32.

2 Dunbar E, Yachnis AT: Glioma diagnosis: immunohistochemistry and beyond. Adv Anat Pathol 2010;17:187-201.

3 Rulseh AM, Keller J, Klener J, Sroubek J, Dbaly V, Syrucek M, Tovarys F, Vymazal J: Long-term survival of patients suffering from glioblastoma multiforme treated with tumor-treating fields. World J Surg Oncol 2012;10:220.

4 Henriksson R, Asklund T, Poulsen HS: Impact of therapy on quality of life, neurocognitive function and their correlates in glioblastoma multiforme: a review. J Neurooncol 2011;104:639-646.

$5 \quad$ Hadjipanayis CG, Van Meir EG: Brain cancer propagating cells: biology, genetics and targeted therapies. Trends Mol Med 2009;15:519-530.

6 Hadjipanayis CG, Van Meir EG: Tumor initiating cells in malignant gliomas: biology and implications for therapy. J Mol Med (Berl) 2009;87:363-374.

7 Hirokawa N, Tanaka Y: Kinesin superfamily proteins (KIFs): Various functions and their relevance for important phenomena in life and diseases. Exp Cell Res 2015;334:16-25.

8 Hung PF, Hong TM, Hsu YC, Chen HY, Chang YL, Wu CT, Chang GC, Jou YS, Pan SH, Yang PC: The motor protein KIF14 inhibits tumor growth and cancer metastasis in lung adenocarcinoma. PLoS One 2013;8:e61664.

9 Miki H, Okada Y, Hirokawa N: Analysis of the kinesin superfamily: insights into structure and function. Trends Cell Biol 2005;15:467-476.

10 Carleton M, Mao M, Biery M, Warrener P, Kim S, Buser C, Marshall CG, Fernandes C, Annis J, Linsley PS: RNA interference-mediated silencing of mitotic kinesin KIF14 disrupts cell cycle progression and induces cytokinesis failure. Mol Cell Biol 2006;26:3853-3863.

11 Molina I, Baars S, Brill JA, Hales KG, Fuller MT, Ripoll P: A chromatin-associated kinesin-related protein required for normal mitotic chromosome segregation in Drosophila. J Cell Biol 1997;139:1361-1371.

12 Gruneberg U, Neef R, Li X, Chan EH, Chalamalasetty RB, Nigg EA, Barr FA: KIF14 and citron kinase act together to promote efficient cytokinesis. J Cell Biol 2006;172:363-372.

13 Ohkura H, Torok T, Tick G, Hoheisel J, Kiss I, Glover DM: Mutation of a gene for a Drosophila kinesin-like protein, Klp38B, leads to failure of cytokinesis. J Cell Sci 1997;110:945-954. 


\section{Cellular Physiology Cell Physiol Biochem 2015;37:1659-1670

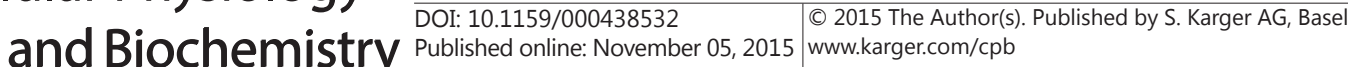 \\ Huang et al.: Oncogenic Role of KIF14 in Human Glioblastoma}

14 Xu H, Choe C, Shin SH, Park SW, Kim HS, Jung SH, Yim SH, Kim TM, Chung YJ: Silencing of KIF14 interferes with cell cycle progression and cytokinesis by blocking the p27(Kip1) ubiquitination pathway in hepatocellular carcinoma. Exp Mol Med 2014;46:e97.

15 Markowski J, Oczko-Wojciechowska M, Gierek T, Jarzab M, Paluch J, Kowalska M, Wygoda Z, Pfeifer A, Tyszkiewicz T, Jarzab B, Niedzielska I, Borgiel-Marek H: Gene expression profile analysis in laryngeal cancer by high-density oligonucleotide microarrays. J Physiol Pharmacol 2009;60:57-63.

16 Singel SM, Cornelius C, Batten K, Fasciani G, Wright WE, Lum L, Shay JW: A targeted RNAi screen of the breast cancer genome identifies KIF14 and TLN1 as genes that modulate docetaxel chemosensitivity in triple-negative breast cancer. Clin Cancer Res 2013;19:2061-2070.

17 Theriault BL, Cybulska P, Shaw PA, Gallie BL, Bernardini MQ: The role of KIF14 in patient-derived primary cultures of high-grade serous ovarian cancer cells. J Ovarian Res 2014;7:123.

18 Wang Q, Wang L, Li D, Deng J, Zhao Z, He S, Zhang Y, Tu Y: Kinesin family member 14 is a candidate prognostic marker for outcome of glioma patients. Cancer Epidemiol 2013;37:79-84.

19 Ding D, Wei S, Song Y, Li L, Du G, Zhan H, Cao Y: Osthole exhibits anti-cancer property in rat glioma cells through inhibiting PI3K/Akt and MAPK signaling pathways. Cell Physiol Biochem 2013;32:1751-1760.

20 Liu E, Kuang Y, He W, Xing X, Gu J: Casticin induces human glioma cell death through apoptosis and mitotic arrest. Cell Physiol Biochem 2013;31:805-814.

21 Yuan Q Gao W, Liu B, Ye W: Upregulation of miR-184 enhances the malignant biological behavior of human glioma cell line A172 by targeting FIH-1. Cell Physiol Biochem 2014;34:1125-1136.

22 Naito S, von Eschenbach AC, Giavazzi R, Fidler IJ: Growth and metastasis of tumor cells isolated from a human renal cell carcinoma implanted into different organs of nude mice. Cancer Res 1986;46:4109-4115.

23 Tomayko MM, Reynolds CP: Determination of subcutaneous tumor size in athymic (nude) mice. Cancer Chemother Pharmacol 1989;24:148-154.

24 Arora K, Talje L, Asenjo AB, Andersen P, Atchia K, Joshi M, Sosa H, Allingham JS, Kwok BH: KIF14 binds tightly to microtubules and adopts a rigor-like conformation. J Mol Biol 2014;426:2997-3015.

25 Nomura N, Nagase T, Miyajima N, Sazuka T, Tanaka A, Sato S, Seki N, Kawarabayasi Y, Ishikawa K, Tabata S: Prediction of the coding sequences of unidentified human genes. II. The coding sequences of 40 new genes (KIAA0041-KIAA0080) deduced by analysis of cDNA clones from human cell line KG-1 (supplement). DNA Res 1994;1:251-262.

26 Basavarajappa HD, Corson TW: KIF14 as an oncogene in retinoblastoma: a target for novel therapeutics? Future Med Chem 2012;4:2149-2152.

27 Corson TW, Huang A, Tsao MS, Gallie BL: KIF14 is a candidate oncogene in the 1q minimal region of genomic gain in multiple cancers. Oncogene 2005;24:4741-4753.

28 Kim TM, Yim SH, Shin SH, Xu HD, Jung YC, Park CK, Choi JY, Park WS, Kwon MS, Fiegler H, Carter NP, Rhyu MG, Chung YJ: Clinical implication of recurrent copy number alterations in hepatocellular carcinoma and putative oncogenes in recurrent gains on 1q. Int J Cancer 2008;123:2808-2815.

29 Corson TW, Gallie BL: KIF14 mRNA expression is a predictor of grade and outcome in breast cancer. Int J Cancer 2006;119:1088-1094.

30 Corson TW, Zhu CQ Lau SK, Shepherd FA, Tsao MS, Gallie BL: KIF14 messenger RNA expression is independently prognostic for outcome in lung cancer. Clin Cancer Res 2007;13:3229-3234.

31 Madhavan J, Coral K, Mallikarjuna K, Corson TW, Amit N, Khetan V, George R, Biswas J, Gallie BL, Kumaramanickavel G: High expression of KIF14 in retinoblastoma: association with older age at diagnosis. Invest Ophthalmol Vis Sci 2007;48:4901-4906.

32 Theriault BL, Pajovic S, Bernardini MQ Shaw PA, Gallie BL: Kinesin family member 14: an independent prognostic marker and potential therapeutic target for ovarian cancer. Int J Cancer 2012;130:1844-1854.

33 Yang T, Zhang XB, Zheng ZM: Suppression of KIF14 expression inhibits hepatocellular carcinoma progression and predicts favorable outcome. Cancer Sci 2013;104:552-557.

34 Singel SM, Cornelius C, Zaganjor E, Batten K, Sarode VR, Buckley DL, Peng Y, John GB, Li HC, Sadeghi N, Wright WE, Lum L, Corson TW, Shay JW: KIF14 promotes AKT phosphorylation and contributes to chemoresistance in triple-negative breast cancer. Neoplasia 2014;16:247-256. 